\title{
Potential Gains from Sector Timing in Taiwan
}

\author{
Heng-Hsing Hsieh \\ University of the Western Cape, South Africa \\ ahsieh@uwc.ac.za
}

\begin{abstract}
The dominance of the electronic sector in the Taiwanese stock market and the relatively low historical correlation between the Taiwanese electronic and financial sector indexes call for the exploration of sector diversity in the Taiwanese stock market. This study investigates the effectiveness of sector timing in Taiwan by evaluating the likely outcomes from switching between the electronic and the financial indexes for data spanning the period December 1999 through December 2012. The proposed sector timing strategy could be implemented using Taiwanese sector index futures. The market timer is assumed to have different timing abilities in the electronic-dominant market and the financial-dominant market. The main results of the research include that when transaction costs are taken into consideration, significant sector timing ability is required to beat the sector benchmark; and it is more important to improve the ability in timing the financial-dominant market in Taiwan.
\end{abstract}

Keywords: Taiwan stock exchange, market timing, sector rotation, market segmentation, efficient market hypothesis, Monte Carlo simulation

\section{Introduction}

Globally Taiwan is known as "the technology island", where the Taiwanese information and communication technology (ICT) industry plays an important role. In 2009, Taiwan accounted for more than 80 percent of the world's PC production. In 2010, Taiwan had the third highest number of ICT companies listed on the world's top ICT 100 companies by revenue, following the U.S. and Japan (Jeong, 2012). According to the data provided by the Taiwan Industrial Development Bureau of the Ministry of Economic Affairs, in 2011 Taiwan had the highest market share in the production of notebook, netbook, desktop, motherboard, server system, LCD monitors, digital camera, IC foundry and IC package, etc. ${ }^{1}$ Wellknown Taiwanese original equipment/design manufacturer (OEM/ODM) giant Hon-Hai Precision Industry (its trade name is known as Foxconn) assembles approximately 40 percent of all consumer electronic products world-wide (Barboza, Lattman and Rampell, 2012). Taiwanese-based ICT brands such as Acer and Asusare ranked amongst the top five largest personal computer (PC) manufacturers worldwide, alongside Hewlett-Packard, Lenovo and Dell. ${ }^{2}$

Due to the economic significance of the Taiwan ICT industry, investors in Taiwan often view the ICT industry as a separate market segment from other sectors. The sale of ICT-related products has been the primary source of export revenue for the Taiwanese economy. The export-oriented ICT industry in Taiwan is generally negatively affected by the strength of the New Taiwanese dollar (NT\$) compared to firms operating in the traditional manufacturing and financial services industry that hold most of their assets in New Taiwanese dollars. In addition, the trading value for Taiwanese ICT companies account for over 60 percent of the trading activities on the Taiwan Stock Exchange. Following the launch of the Taiwan Stock Exchange Capitalization-Weighted Stock Index (TAIEX) futures on 21 July 1998, the Taiwan Futures Exchange (TAIFEX) introduced two sector index futures, namely the Taiwan Stock Exchange Electronic Sector Index futures and the Taiwan Stock Exchange Financial Sector Index futures one year later on 21 July 1999. With liquid futures contracts on the local electronic and financial sector indexes, investors have easy access to gain unique exposures in these two distinctive Taiwanese market segments.

This study investigates the likelihood of profitability from sector timing between the electronic sector and the financial sector using Taiwanese sector index futures. Research on potential gains from market timing is pioneered by Sharpe (1975) based on a probability analysis of likely outcomes for imperfect timing strategies. Chua, Woodward and To (1987) improve the methodology of Sharpe (1975) by assigning

\footnotetext{
${ }^{1}$ Sector Analysis Report, (2012), The Trade Council of Denmark, Taipei, January

${ }^{2}$ http://www.gartner.com/newsroom/id/2301715
} 
various permutations of bull and bear market forecasting abilities for a hypothetical market timer, and estimating potential gains using Monte Carlo simulation. Empirical studies of this nature generally focuses on the level of accuracy required to benefit from market timing strategies that switches between stocks and treasuries in bull and bear markets respectively. It could be argued that market timing studies could be expanded to explore the sector or style diversity in the market. Prior significant studies that made this attempt are limited to Kester (1990) and Bauer and Dahquist (2001) who evaluate potential gains from switching between large caps, small caps and bonds. By investigating the potential gains from switching between distinctive sectors or styles that are counter-cyclical in nature, the practicality of sector or style timing as an investment strategy could be established. Motivated by this argument, the primary objective of this paper is to investigate whether the market segmentation in the Taiwanese economy provides potential opportunities for profitable sector timing strategies. The rest of the paper is organized as follows: significant prior literature is first discussed in Section 2; followed by a detailed description of the data and methodology employed in this research in Section 3. Section 4 discusses the results of potential benefits from sector timing in Taiwan; followed by conclusion and recommendations based on the significant findings of the research.

\section{Literature Review}

Theoretical Background: Market timing refers to the practice of switching between asset classes, sectors or investment styles based on the forecasts of future movements in the market. Such practice is in direct contradiction to the random walk hypothesis (RWH), which states that the movements of asset prices are completely random and thus cannot be predicted. Market timers often rely on technical indicators and charting tools to support their decisions. According to the efficient market hypothesis (EMH) of Fama (1970), technical analysis and trading rules are fruitless since they would have already been incorporated in asset prices in any market that is classified as weak-form (the lowest level of an efficient market).In an efficient market, economic agents are rational expected utility maximizers who base their trading decisions on information available in the market. Since technical indicators are derived from historical information, they cannot be used to outperform the market. An alternative school of thought, behavioural finance, argues that investors are irrational and are prone to making systematic errors in their trading behaviour. Proponents of technical analysis argue that price trends and volume data reflect the cognitive biases of investors, which results in the predictability of market timing. In the presence of investor irrationality, the timing of persistent overshooting of asset prices and their subsequent reversals are predictable. DeBondt \& Thaler $(1985 ; 1987)$ identify significant market reversals of portfolios formed by past 36-month winners and losers on the New York Stock Exchange (NYSE) over the period from 1933 to 1982. Jegadeesh \& Titman (1993) discover the persistence of momentum for U.S. stocks with above-average prior 3- to 12-month returns over the period from 1965 to 1989.

Significant Prior Literature: Despite the theoretical debate regarding the practicality of market timing, Sharpe (1975) demonstrates a significant $14.86 \%$ annual return available to market timers who could perfectly switch between U.S. stocks and Treasury bills over the period from 1934 to 1972, compared to $10.64 \%$ annual return for the buy-and-hold strategy over the same period. However, it is unlikely for a market timer to possess perfect timing ability, and hence it is more practical to evaluate potential gains to imperfect timing based on various levels of forecasting ability. Sharpe (1975) assign various levels of forecasting accuracy for a hypothetical market timer in order to estimate the minimum level of forecasting accuracy that is required to benefit from market timing. Study results reveal that potential gains to market timing are rare as more than $74 \%$ accuracy is required to beat the buy-and-hold strategy in stocks on a risk-adjusted basis.

Chua, Woodward \& To (1987) relax the assumption that the market timer has the same forecasting ability in both bull and bear markets and estimate potential gains from market timing in the Canadian Stock Exchange based on various permutations of bull and bear forecasting accuracies over the period from 1950 to 1983. Chua et al. (1987) compute the average return of the timing strategy in excess of the buyand-hold strategy in stocks for each permutation of bull and bear forecasting accuracy after 10,000 iterations are simulated for each permutation. In addition, the authors compute the win/loss ratio for each permutation to provide an indication of the likelihood that the market timing strategy will beat the buy-and-hold strategy. They argue that the win/loss ratio is a more relevant measure since it filters out the situations where the buy-and-hold investor and the market timer are both holding stocks. The results of their study indicate that a more than $70 \%$ joint accuracy is required to beat the buy-and-hold strategy; 
and it is more important to predict the upcoming bull markets than bear markets. The analysis of the win/loss ratio across various permutations of bull and bear forecasting accuracies also indicates that the large gains foregone in bull markets outweigh the losses avoided in the bear markets. This conclusion is supported by Droms (1989), who evaluates the potential gains from market timing in the U.S. stock markets over the period from 1926 to 1986. Shilling (1992), on the other hand, argues that substantial effort is required to recover from large losses incurred in a market crash, and the ability to preserve capital during turbulent times is crucial for large gains when the market rebounds.

Using the same data employed by Sharpe (1975), Clarke, FitzGerald, Berent and Statman (1989) develop a single factor model that includes changes in GNP as the predictor for stock returns. Contrary to the findings of prior research, significant gains are achieved by the market timing strategy based on signals generated by the single factor model. Clarke et al. (1987) concludes that even modest additional information can improve the benefits of market timing. Instead of testing potential gains from timing between bull and bear markets using stocks and Treasuries, Kester (1990) investigates potential gains from switching between large caps, small caps and Treasuries in the U.S. stock markets based on data from 1934 to 1988. Various levels of transaction costs and revision frequencies are examined to determine the sensitivities of potential gains to changes in these two key variables. The results indicate that the maximum profit of $28.26 \%$ per annum is available to investors who were able to perfectly switch between small caps and Treasuries at $0.25 \%$ trading cost with monthly revision; and the minimum level of accuracy (56\%) required to benefit from market timing is to switch between large caps and small caps with quarterly revision at $0.25 \%$ trading cost. However, the required minimum accuracy to benefit from market timing is raised to $62 \%$ when the trading cost is $0.50 \%$; and to $70 \%$ if the trading cost is $2 \%$. Overall, the sensitivity analysis suggests that the trading costs required for switching in between asset classes is a crucial factor for the success of a market timer. Bauer and Dahquist (2001) extend prior studies on the timing of limited asset classes to include simulations on random switches between a variety of U.S. asset classes, including large caps, small caps, corporate bonds and Treasuries in the U.S. based on data over the period from 1926 to 1999. The authors find that switching between fewer assets classes are more beneficial compared to switching between many asset classes.

De Chassart and Firer (2001) test the potential gains from three market timing strategies on the Johannesburg Stock Exchange (JSE). The three strategies under examination include a traditional market timing strategy, a bull timing strategy and a bear timing strategy. The traditional market timing strategy switches between the stocks and money market instruments depending on whether a bull or a bear market is forecasted. The bull timing strategy invests in money market instruments and purchases call options on the market index when a bull market is forecasted. The bear timing strategy has long positions in the market index and purchases put options on the market index (i.e. a synthetic protective put strategy) when a bear market is forecasted. The study makes great practical sense as hedging using options is a common practice adapted by traders. In addition, the authors highlighted that the traditional timing strategy has severe liquidity constraint in illiquid markets. The study results reveal that the bear timing strategy that hedges the stock investment using put options is the most effective market timing strategy on the JSE.

The empirical literature discussed above suggests that potential gains from market timing are available to investors who possess substantial timing ability and are able to trade at lower costs. With regard to whether trading practices in general adds value to investors' portfolios in Taiwan, Barber, Lee, Liu \& Odean (2005) test whether institutional investors have advantage over individual investors using all trade data for all market participants over the period from 1995 to 1999. Their results indicate that institutional investors gain even when transaction costs are taken into account; while individual investors are found to lose substantially from their trades over the examination period. In addition, almost all individual investors' trading losses are attributed to their aggressive orders. In recognition of the influences of fiscal and monetary policy in stock market performance, Chen and Chen (2011) evaluate the performance of a standard market timing strategy that invests in the market during a declining interest rate regime and shifts to Treasuries during a rising interest rate regime in Taiwan using data from 1995 to 2008. They compare the performance of the standard market timing strategy to the buy-and-hold strategy and the sector rotation strategy that invests in cyclical sectors during expansionary monetary periods and shifts to noncyclical sectors during restrictive monetary periods. It is found that the standard market timing strategy outperforms both the buy-and-hold strategy and the sector rotation strategy. Chen, Chuang, Lin and Lan (2013) examine a sample of 77 Taiwanese mutual funds over the period from 
2005 to 2009. Their results indicate a lack of market timing ability and a presence of stock selection ability for Taiwanese mutual fund managers.

\section{Methodology}

Descriptive Statistics of Research Data: The monthly Taiwanese futures contracts call for settlement on the third Wednesday of the delivery month. The settlement values of the monthly futures contracts on the TAIEX index, electronic index and financial index are extracted from the Taiwan Futures Exchange (TAIFEX) official website (www.taifex.com.tw)for the examination period from 16 December 1999 through 19 December 2012 based on the settlement date of the futures contracts. The convergence property ensures that the spot values of the underlying indexes are in line with the settlement values of the index futures contracts on the settlement day to prevent arbitrage opportunities. The sector index performance statistics over the examination period are summarized in Table 1. Panel (a) of Table 1 displays the correlation coefficient between the Taiwanese stock market index returns. Although both the electronic and financial index returns are highly correlated with the TAIEX index returns, the correlation coefficient between the two sector indexes is only $67.28 \%$. This observation is indicative of some degree of market segmentation in the Taiwan stock exchange. The dominance of the electronic sector on the Taiwanese stock market is also evident in that the correlation coefficient between the electronic index returns and the TAIEX index returns is more than $10 \%$ higher compared to the correlation coefficient between the financial index returns and the TAIEX index returns.

Panel (b) in Table 1 provides the monthly returns, standard deviation and maximum drawdown of the Taiwanese stock market indexes. The performance statistics of the hypothetical perfect timing strategy that calls for switching between investments in the electronic and financial sectors over the examination period is also documented. Using the data extracted on the settlement dates of the Taiwanese index futures, a hypothetical market timer is assumed to be able to close-out the existing index futures contracts at the monthly settlement value; and switch over to the new futures contracts for the alternative index at the cost of the opening value. The financial index earns higher monthly returns of $0.35 \%$ on average with lower maximum drawdown of $-60.85 \%$ compared to the TAIEX index and the electronic index. Despite the higher average returns earned by the financial index, the electronic index out performs the financial index in 81 out of 156 months. The perfect timing strategy, on the other hand, achieves an average monthly return of $2.52 \%$ with a limited maximum drawdown of $48.82 \%$ after $1 \%$ transaction costs are deducted from switching. The perfect timing strategy seems to have limited impact on the total risk of the portfolio, and the most diversified TAIEX index still has the lowest monthly standard deviation of $8.12 \%$.

Table 1: Index Performance Statistics (16 December 1999 19 December 2012)

\begin{tabular}{llll}
\hline Panel (a) Correlation: & & & \\
TAIEX: & TAIEX & Electronic & Financials \\
Electronic: & $100 \%$ & & \\
Financial: & $95.66 \%$ & $100 \%$ & \\
& $82.83 \%$ & $67.28 \%$ & $100 \%$
\end{tabular}

Panel (b) Monthly Performance Statistics:

$\begin{array}{llll} & \text { Returns } & \text { Stdev } & \text { Max Drawdown } \\ \text { TAIEX: } & 0.32 \% & 8.12 \% & -63.50 \% \\ \text { Electronic: } & 0.24 \% & 9.36 \% & -70.18 \% \\ \text { Financial: } & 0.35 \% & 9.17 \% & -60.85 \% \\ \text { Perfect Timing: } & 2.52 \% & 8.91 \% & -48.82 \%\end{array}$

(1\% Transaction cost)

Electronics> Financial:81 months (Total: 156 months)

Simulation Assumptions: In order to estimate the potential gains from imperfect sector timing in Taiwan, assumptions need to be made regarding the method of forecasting and switching. A hypothetical market timer is assumed to switch between the Taiwanese electronic index and the Taiwanese financial index depending on whether an electronic-dominant market or a financial-dominant market is forecasted for the coming month. Defining the electronic-dominant market as the period in which the electronic 
index earns higher returns than the financial index; and vice versa for the financial-dominant market, the market timer is assumed to have different forecasting abilities in the electronic-dominant market and the financial-dominant market. The sector timing strategy calls for investments in (or switching to) the sector with higher forecasted returns at $1 \%$ transaction costs, with the decision to be revised on a monthly basis. Defining the potential gains from the sector timing strategy as the return of the strategy in excess of the buy-and-hold strategy in the sector index, the potential gains derived from various permutations of forecasting accuracies in the electronic-dominant market and in the financial-dominant market are evaluated against the buy-and-hold strategy in the electronic index and the financial index respectively. The forecasting accuracy of the market timer in the electronic-dominant market is the probability of forecasting an electronic-dominant market, given that the electronic sector indeed outperforms the financial sector for the period. Similarly, the probability of the market timer in forecasting a financialdominant market correctly represents the market timer's forecasting accuracy in the financial-dominant market. Various permutations for the levels of forecasting accuracy in each sector-dominant market are tested in both sector-dominant markets. Empirical tests on market timing do not include results obtained from less than $50 \%$ forecasting accuracy because it is deemed that a market timer who gets his/her predictions correct $50 \%$ of the time does not have any forecasting ability. Thus, the permutation starts with $50 \%$ forecasting accuracy in both sector-dominant markets, with the levels of accuracy to be raised at $10 \%$ increments until the potential gains for all possible permutations between $50 \%$ and $100 \%$ in each market are estimated.

The Bivariate Log Normal Distribution of Sector Index Returns: Chua et al. (1987) propose the use of the simulated data rather than the actual data to evaluate the potential gains from market timing for two reasons. First, the number of observations for the actual data is very limited compared to the simulated data. Second, due to the fact that there is only one history of events in the actual data, the interpretation of past data is restricted. On the other hand, the simulated data allows for analysis on the potential returns and events that might have, or yet to occur. In order to account for the co-movements between the sector indexes returns, a bivariate lognormal distribution proposed by Chua et al. (1987) is required for simulating the sector index returns. The assumption that the sector index returns follow a lognormal distribution prevents simulated returns from falling below $-100 \%$.

Let $R_{\text {elec }}$ and $R_{\text {fin }}$ represent the monthly returns on the electronic and financial sector indexes over the examination period; Yelec $=\ln \left(1+R_{\text {elec }}\right)$ and $Y_{\text {fin }}=\ln \left(1+R_{\text {fin }}\right) ; \mu_{\text {elec }}$ and $\mu_{\text {fin }}$ represent the mean of $Y_{\text {elec }}$ and $Y_{\text {fin }}$; and $\sigma_{\text {elec }}$ and $\sigma_{\text {fin }}$ represent the standard deviation of $Y_{\text {elec }}$ and the standard deviation of $Y_{\text {fin }}$ respectively, the conditional probability distribution of $Y_{\text {fin }}$ given the estimated value of $Y_{\text {elec }}$ is depicted in Equation 1:

$f\left(Y_{\text {fin }} \mid Y_{\text {elec }}\right)=1 /\left(\sqrt{2 \pi} \times \sigma_{\text {fin }, \text { elec }}\right) \times \exp \left(-\left(Y_{\text {elec }}-\propto_{\text {fin }, \text { elec }}-\beta_{\text {fin }, \text { elec }} Y_{\text {fin }}\right)^{2} / 2 \sigma_{\text {fin }, \text { elec }}^{2}\right)$

Where

$\alpha_{\text {fin }, \text { elec }}=\mu_{\text {fin }}-\mu_{\text {elec }} \times \rho_{\text {elec }, \text { fin }} \times\left(\sigma_{\text {fin }} / \sigma_{\text {elec }}\right) ;$

$\beta_{\text {fin }, \text { elec }}=\rho_{\text {elec }, \text { fin }} \times\left(\sigma_{\text {fin }} / \sigma_{\text {elec }}\right) ;$ and

$\sigma_{\text {fin }, \text { elec }}^{2}=\sigma_{\text {fin }}^{2} \times\left(1-\rho_{\text {elec }, \text { fin }}^{2}\right)$.

The bivariate log normal distribution above has mean equal to $\alpha_{f i n, e l e c}+\beta_{f i n, \text { elec }} \times Y_{\text {elec }}$ and standard deviation equal to $\sigma_{\text {fin,elec }}$. Two sets of 10,000 random numbers are generated from the standard normal distribution with mean of zero and standard deviation of one. Denoting the first set of random numbers as $Z_{\text {elec }}$ and the second set of random numbers as $Z_{\text {fin }}, 10,000$ simulated returns are generated for the electronic index and financial index using Equation (2) and Equation (3) respectively:

$\hat{R}_{\text {elec }}=\exp \left(Z_{\text {elec }} \times \sigma_{\text {elec }}+\mu_{\text {elec }}\right)-1$

$\hat{R}_{\text {fin }}=\exp \left(Z_{\text {fin }} \times \sigma_{\text {fin }, \text { elec }}+\propto_{\text {fin }, \text { elec }}+\beta_{\text {fin }, \text { elec }} \times \mu_{\text {elec }}\right)-1$

Based on the comparison between the simulated sector index returns, each of the 10,000 iterations is classified as either an electronic-dominant market or a financial-dominant market. A set of 10,000 normally-distributed random numbers (denoted $N_{1}$ to $N_{10,000}$ ) between $0 \%$ and $100 \%$ are then generated to determine whether the market timer forecasts the dominant sector in each of the 10,000 iterations successfully. If the first iteration has an electronic dominance, the level of forecasting accuracy in the electronic-dominant market is compared to the first random number, $N_{1}$. If the level of accuracy in the electronic-dominant market is higher than $N_{1}$, the market timer has predicted electronic dominance in the market successfully and earns the simulated return on the electronic index for the first period. On the 
other hand, if the forecasting accuracy in the electronic-dominant market is lower than $N_{1}$, the market timer has forecasted a financial-dominant market while the simulated iteration is indeed electronicdominant. As a result, the relatively lower simulated return on the financial sector index is earned. Similarly, if the financial-dominance in the market is simulated in the iteration, the market timer's forecasting accuracy for the financial-dominant market is compared to $N_{1}$ to determine whether the market timer will earn the simulated financial index return based on the successful forecast; or the simulated electronic index return based on the inaccurate forecast. Since $N$ represents a normallydistributed random number with a mean of $50 \%$, a market timer only has a higher probability of earning the dominant sector return in the iteration if he/she possesses a higher than $50 \%$ forecasting accuracy in the dominant sector. After 10,000 iterations for each permutation of forecasting accuracies are evaluated, the average return, standard deviation, excess return in each sector, standard deviation of excess returns and the win/loss ratio are evaluated to determine the minimum levels of accuracy required to gain from sector timing in Taiwan.

\section{Results}

Simulated Return and Standard Deviation from Sector Timing: The simulated returns and standard deviation for each permutation of forecasting accuracies in the electronic-dominant market and the financial-dominant market are demonstrated in Table 2. Each row in Table 2 represents improvements in performance when the level of forecasting accuracy in the financial-dominant market increases from $50 \%$ to $100 \%$, holding the level of forecasting accuracy in the electronic-dominant market constant. Similarly, each column in Table 2 shows the sensitivity of the market timer's performance to changes in the forecasting accuracy in the electronic-dominant market.

Table 2: Simulated Return and Standard Deviation

\begin{tabular}{|c|c|c|c|c|c|c|c|}
\hline \multirow{2}{*}{\multicolumn{2}{|c|}{ (n) }} & \multicolumn{6}{|c|}{ Financials Timing Accuracy (\%) } \\
\hline & & $\mathbf{5 0 \%}$ & $60 \%$ & $70 \%$ & $80 \%$ & $90 \%$ & $100 \%$ \\
\hline \multicolumn{8}{|c|}{$\begin{array}{l}\text { Electronic Timing Accuracy } \\
(\%)\end{array}$} \\
\hline \multirow[t]{2}{*}{$50 \%$} & Return & $-0.16 \%$ & $0.16 \%$ & $0.46 \%$ & $0.80 \%$ & $1.14 \%$ & $1.44 \%$ \\
\hline & Stdev & $9.45 \%$ & $9.48 \%$ & $9.47 \%$ & $9.45 \%$ & $9.43 \%$ & $9.35 \%$ \\
\hline \multirow[t]{2}{*}{$60 \%$} & Return & $0.11 \%$ & $0.44 \%$ & $0.74 \%$ & $1.08 \%$ & $1.42 \%$ & $1.72 \%$ \\
\hline & Stdev & $9.47 \%$ & $9.48 \%$ & $9.47 \%$ & $9.44 \%$ & $9.41 \%$ & $9.32 \%$ \\
\hline \multirow[t]{2}{*}{$70 \%$} & Return & $0.43 \%$ & $0.76 \%$ & $1.06 \%$ & $1.40 \%$ & $1.74 \%$ & $2.04 \%$ \\
\hline & Stdev & $9.52 \%$ & $9.53 \%$ & $9.50 \%$ & $9.46 \%$ & $9.42 \%$ & $9.31 \%$ \\
\hline \multirow[t]{2}{*}{$80 \%$} & Return & $0.74 \%$ & $1.07 \%$ & $1.37 \%$ & $1.71 \%$ & $2.04 \%$ & $2.35 \%$ \\
\hline & Stdev & $9.54 \%$ & $9.53 \%$ & $9.49 \%$ & $9.44 \%$ & $9.39 \%$ & $9.28 \%$ \\
\hline \multirow[t]{2}{*}{$90 \%$} & Return & $1.04 \%$ & $1.36 \%$ & $1.66 \%$ & $2.00 \%$ & $2.34 \%$ & $2.65 \%$ \\
\hline & Stdev & $9.55 \%$ & $9.54 \%$ & $9.49 \%$ & $9.43 \%$ & $9.37 \%$ & $9.24 \%$ \\
\hline \multirow[t]{2}{*}{$100 \%$} & Return & $1.32 \%$ & $1.65 \%$ & $1.95 \%$ & $2.29 \%$ & $2.62 \%$ & $2.93 \%$ \\
\hline & Stdev & $9.54 \%$ & $9.52 \%$ & $9.46 \%$ & $9.39 \%$ & $9.31 \%$ & $9.18 \%$ \\
\hline
\end{tabular}

Note: The simulated average return and standard deviation for the electronic index futures are $0.28 \%$ and $9.63 \%$ respectively; and the simulated return and standard deviation for the financial index futures are $0.37 \%$ and $9.18 \%$ respectively. The correlation coefficient between the simulated returns for the two sector index futures is $65.74 \%$.

Examining the simulated returns in Table 2 reveals that an investor who has no timing ability (i.e. a joint $50 \%$ forecasting accuracy) makes a monthly loss of $0.16 \%$ on average. Positive average monthly returns are available once the market timer possesses some degree of forecasting power in either one of the sector-dominant markets. When the joint forecasting accuracy for the two sector-dominant markets is $100 \%$ (i.e. perfect foresight), the market timer achieves an average monthly return of $2.93 \%$ with standard deviation of $9.18 \%$. These statistics are slightly overstated compared to the actual average monthly return of $2.52 \%$ with standard deviation of $8.91 \%$ for the perfect sector timing strategy shown in Table 1 . The overstated return and risk statistics for the perfect timing strategy are attributed to the 
upward biases inherent in the return and risk simulations for the underlying sector indexes. The note for Table 2 indicates that the simulated average monthly return and standard deviation for the electronic index are $0.28 \%$ and $9.63 \%$ respectively, which are slightly higher than the actual average monthly return of $0.24 \%$ and standard deviation of $9.36 \%$ in Table 1 . On the other hand, the simulated average monthly return and standard deviation for the financial index are $0.37 \%$ and $9.18 \%$ respectively, which are very close to the actual figures of $0.35 \%$ and $9.17 \%$ in Table 1 . The correlation coefficient of $65.74 \%$ between the two simulated index returns generated from the bivariate lognormal distribution is in line with the actual correlation coefficient indicated in Table 1 (67.28\%). Overall, the simulated results seem to exhibit a slight upward bias for the performance of the sector indexes compared to the actual data extracted. This implies that the actual potential gains available from sector timing in Taiwan might not be as optimistic as indicated by the test results of this paper.

Sector Timing Strategy versus Buy-and-Hold: Table 3 measures the performance of the simulated sector timing strategy against the buy-and-hold strategy in the electronic index. The potential gains are represented by the average excess returns over the buy-and-hold strategy in the electronic index. For a market timer to earn higher returns than the buy-and-hold strategy in the electronic sector on average, he/she must have at least $60 \%$ forecasting accuracies in both sector-dominant markets. Otherwise, $70 \%$ or higher forecasting accuracy is required in one of the sector-dominant markets.

Table 3: Sector Timing Strategy versus Buy-and-Hold in the Electronic Index

\begin{tabular}{|c|c|c|c|c|c|c|c|}
\hline \multirow{2}{*}{\multicolumn{2}{|c|}{$\begin{array}{l}\text { Electronic-Dominant } \\
\text { Market } \\
\text { Timing Accuracy (\%) }\end{array}$}} & \multicolumn{6}{|c|}{ Financial-Dominant Market Timing Accuracy (\%) } \\
\hline & & $50 \%$ & $60 \%$ & $70 \%$ & $80 \%$ & $90 \%$ & $100 \%$ \\
\hline \multirow[t]{3}{*}{$50 \%$} & Excess Return & $-0.45 \%$ & $-0.12 \%$ & $0.18 \%$ & $0.52 \%$ & $0.86 \%$ & $1.16 \%$ \\
\hline & Stdev (excess R\%) & $5.45 \%$ & $5.72 \%$ & $5.95 \%$ & $6.18 \%$ & $6.37 \%$ & $6.54 \%$ \\
\hline & Win/Loss & 0.47 & 0.59 & 0.72 & 0.88 & 1.05 & 1.22 \\
\hline \multirow[t]{3}{*}{$60 \%$} & Excess Return & $-0.17 \%$ & $0.16 \%$ & $0.46 \%$ & $0.80 \%$ & $1.13 \%$ & $1.44 \%$ \\
\hline & Stdev (excess R\%) & $5.18 \%$ & $5.45 \%$ & $5.67 \%$ & $5.89 \%$ & $6.08 \%$ & $6.24 \%$ \\
\hline & Win/Loss & 0.49 & 0.62 & 0.76 & 0.92 & 1.11 & 1.30 \\
\hline \multirow[t]{3}{*}{$70 \%$} & Excess Return & $0.15 \%$ & $0.48 \%$ & $0.78 \%$ & $1.12 \%$ & $1.45 \%$ & $1.76 \%$ \\
\hline & Stdev (excess R\%) & $4.83 \%$ & $5.10 \%$ & $5.32 \%$ & $5.54 \%$ & $5.72 \%$ & $5.87 \%$ \\
\hline & Win/Loss & 0.52 & 0.66 & 0.81 & 0.99 & 1.19 & 1.40 \\
\hline \multirow[t]{3}{*}{$80 \%$} & Excess Return & $0.46 \%$ & $0.79 \%$ & $1.09 \%$ & $1.42 \%$ & $1.76 \%$ & $2.07 \%$ \\
\hline & Stdev (excess R\%) & $4.43 \%$ & $4.70 \%$ & $4.92 \%$ & $5.13 \%$ & $5.31 \%$ & $5.46 \%$ \\
\hline & Win/Loss & 0.54 & 0.69 & 0.85 & 1.04 & 1.27 & 1.49 \\
\hline \multirow[t]{3}{*}{$90 \%$} & Excess Return & $0.75 \%$ & $1.08 \%$ & $1.38 \%$ & $1.72 \%$ & $2.06 \%$ & $2.36 \%$ \\
\hline & Stdev (excess R\%) & $4.02 \%$ & $4.29 \%$ & $4.51 \%$ & $4.72 \%$ & $4.89 \%$ & $5.03 \%$ \\
\hline & Win/Loss & 0.57 & 0.74 & 0.91 & 1.12 & 1.36 & 1.61 \\
\hline \multirow[t]{3}{*}{$100 \%$} & Excess Return & $1.04 \%$ & $1.37 \%$ & $1.67 \%$ & $2.00 \%$ & $2.34 \%$ & $2.65 \%$ \\
\hline & Stdev (excess R\%) & $3.56 \%$ & $3.85 \%$ & $4.06 \%$ & $4.28 \%$ & $4.44 \%$ & $4.58 \%$ \\
\hline & Win/Loss & 0.61 & 0.78 & 0.97 & 1.20 & 1.47 & 1.74 \\
\hline
\end{tabular}

Similar findings are observed when examining the performance of the sector timing strategy against the buy-and-hold strategy in the financial index in Table 4, where a joint forecasting accuracy of at least $60 \%$ in both sector-dominant markets; or $70 \%$ or higher forecasting accuracy is required in either market to achieve positive excess returns on average. It is also noted that the improvements in potential gains are more sensitive to increases in the forecasting accuracy in the financial-dominant market regardless of whether the sector benchmark is the electronic index or the financial index. This is evident in that the potential gains grow faster across columns than across rows in both Table 3 and Table 4 . This result is expected since the financial index is the relatively better performing sector compared to the electronic index. Thus, improving the forecasting accuracy for the financial-dominant market is a more effective way of improving the performance of the market timing strategy. On the other hand, examination of the 
standard deviation of potential gains in Table 3 and Table 4 reveals that the risk of forecasts increases as the forecasting accuracy improves in the sector alternative to the benchmark sector. This is evident in the rising standard deviation across columns in Table 3; and across rows in Table 4. By contrast, the standard deviation of excess returns declines when there is an improvement in the forecasting accuracy in the benchmark sector. The results suggest that it is relatively easier for a financial sector timing expert to beat the electronic sector benchmark since the potential gain increases with decreasing risk when the financial sector timing ability improves. Any other combination will result in a faster growing potential gains accompanied by increases in forecasting risk; or a slower growing potential gains accompanied by declining risk of forecasts.

The win/loss ratio depicts the number of successful switches that results in higher return relative to the number of unsuccessful switches that results in lower return compared to the sector benchmark. As explained by Chua et al. (1987: 55), "This win/loss ratio gives an indication of the odds for improving upon buy-and-hold performance with market timing". As mentioned, the win/loss ratio indicates the probability that the sector timing strategy will earn higher returns than the sector benchmark. The likelihood of beating the sector benchmark is above $50 \%$ when the win/loss ratio is greater than 1.0. Since the win/loss ratio ignores situations in which both the sector timing strategy and the buy-and-hold strategy are investing in the same sector, an improvement in the timing ability in the benchmark sector is less effective compared to an improvement in the timing ability in the alternative sector. This is because an improvement in the timing ability in the benchmark sector merely reduces the number of losses in the denominator of the win/loss ratio. By contrast, an improvement in the timing ability in the alternative sector simultaneously increases the number of wins in the numerator and decreases the number of losses in the denominator of the win/loss ratio. This is evident in that it is more difficult to improve the win/loss ratio across the rows in Table 3; and across the columns in Table 4.

Table 4: Sector Timing Strategy versus Buy-and-Hold in the Financial Index

\begin{tabular}{|c|c|c|c|c|c|c|c|}
\hline \multirow{2}{*}{\multicolumn{2}{|c|}{$\begin{array}{l}\text { Electronic-Dominant } \\
\text { Market } \\
\text { Timing Accuracy (\%) }\end{array}$}} & \multicolumn{6}{|c|}{ Financial-Dominant Market Timing Accuracy (\%) } \\
\hline & & $\mathbf{5 0 \%}$ & $60 \%$ & $70 \%$ & $80 \%$ & $90 \%$ & $100 \%$ \\
\hline \multirow[t]{3}{*}{$50 \%$} & Excess Return & $-0.53 \%$ & $-0.20 \%$ & $0.10 \%$ & $0.43 \%$ & $0.77 \%$ & $1.08 \%$ \\
\hline & Stdev (excess R\%) & $5.61 \%$ & $5.30 \%$ & $5.00 \%$ & $4.61 \%$ & $4.15 \%$ & $3.66 \%$ \\
\hline & Win/Loss & 0.45 & 0.48 & 0.50 & 0.53 & 0.57 & 0.61 \\
\hline \multirow[t]{3}{*}{$60 \%$} & Excess Return & $-0.25 \%$ & $0.07 \%$ & $0.37 \%$ & $0.71 \%$ & $1.05 \%$ & $1.36 \%$ \\
\hline & Stdev (excess R\%) & $5.84 \%$ & $5.54 \%$ & $5.23 \%$ & $4.83 \%$ & $4.38 \%$ & $3.89 \%$ \\
\hline & Win/Loss & 0.56 & 0.59 & 0.62 & 0.66 & 0.72 & 0.76 \\
\hline \multirow[t]{3}{*}{$70 \%$} & Excess Return & $0.07 \%$ & $0.39 \%$ & $0.69 \%$ & $1.03 \%$ & $1.37 \%$ & $1.68 \%$ \\
\hline & Stdev (excess R\%) & $6.09 \%$ & $5.77 \%$ & $5.47 \%$ & $5.07 \%$ & $4.62 \%$ & $4.13 \%$ \\
\hline & Win/Loss & 0.68 & 0.72 & 0.76 & 0.82 & 0.89 & 0.95 \\
\hline \multirow[t]{3}{*}{$80 \%$} & Excess Return & $0.38 \%$ & $0.70 \%$ & $1.00 \%$ & $1.34 \%$ & $1.68 \%$ & $1.98 \%$ \\
\hline & Stdev (excess R\%) & $6.31 \%$ & $5.99 \%$ & $5.68 \%$ & $5.27 \%$ & $4.82 \%$ & $4.33 \%$ \\
\hline & Win/Loss & 0.81 & 0.86 & 0.92 & 1.00 & 1.07 & 1.16 \\
\hline \multirow[t]{3}{*}{$90 \%$} & Excess Return & $0.67 \%$ & $1.00 \%$ & $1.30 \%$ & $1.64 \%$ & $1.97 \%$ & $2.28 \%$ \\
\hline & Stdev (excess R\%) & $6.48 \%$ & $6.16 \%$ & $5.84 \%$ & $5.43 \%$ & $4.97 \%$ & $4.48 \%$ \\
\hline & Win/Loss & 0.96 & 1.02 & 1.09 & 1.18 & 1.29 & 1.40 \\
\hline \multirow[t]{3}{*}{$100 \%$} & Excess Return & $0.96 \%$ & $1.28 \%$ & $1.58 \%$ & $1.92 \%$ & $2.26 \%$ & $2.56 \%$ \\
\hline & Stdev (excess R\%) & $6.63 \%$ & $6.30 \%$ & $5.97 \%$ & $5.55 \%$ & $5.08 \%$ & $4.59 \%$ \\
\hline & Win/Loss & 1.13 & 1.20 & 1.29 & 1.40 & 1.54 & 1.68 \\
\hline
\end{tabular}

An examination of the win/loss ratio in Table 3 shows that the likelihood of beating the electronic sector benchmark is above $50 \%$ if a market timer has forecasting accuracy of $90 \%$ or above in the financialdominant market, even if he/she does not possess any forecasting ability in the electronic-dominant market. On the other hand, a market timer who does not have any predictive power in the financial- 
dominant market is required to switch into all electronic-dominant months (i.e. 100\% accuracy) in order to achieve a win/loss ratio of greater than 1.0. Overall, a joint forecasting accuracy of at least $80 \%$ is required for the win/loss ratio to be 1.0 or above in both Table 3 and Table 4 . This means that significant sector timing ability is required to have a higher probability of beating the sector benchmark, despite the fact that only moderate level of accuracy is required to have positive potential gains on average. This observation indicates that the potential gains are positively skewed even though the benchmark returns are simulated from a bivariate lognormal distribution. The result is attributed to the negative impact of the transaction costs of switching, which simultaneously reduces the number of wins and increases the number of losses in the simulation: every correct switch back to the sector benchmark is recorded as a loss due to the transaction cost.

\section{Conclusion}

This paper evaluates potential gains from sector market timing in Taiwan. A hypothetical sector timing strategy calls for monthly revision of switches between the electronic and financial indexes based on the sector-dominance being predicted in the coming month. The transaction cost of $1 \%$ is assumed during switching between sector indexes. The market timer is assumed to have varying forecasting abilities in the electronic-dominant market and the financial-dominant market. Defining potential gains as the returns of the sector timing strategy in excess of the buy-and-hold strategy in the respective sector benchmarks; and the win/loss ratio as the probability of beating the sector benchmark return, various permutations of forecasting accuracies between the two sector-dominant markets are evaluated using simulated data. Two sets of 10,000 sector index returns are simulated from a bivariate lognormal distribution using the monthly average return, standard deviation and the correlation coefficient between the two sector indexes over the period from 16 December 1999 through 19 December 2012. The main results include that it is more important to improve the forecasting ability in the financial-dominant market regardless of the sector benchmark used in the evaluation; and the risk of forecasts increases as the forecasting accuracy improves in the sector-dominant market alternative to the benchmark sector. As a result, the easiest outperformance is achieved by improving the market timing ability in the financialdominant market when the electronic sector benchmark is used. It is also found that the potential gains are positively skewed due to the negative impact of the transaction cost incurred during switching. Thus, significant sector timing ability is required to achieve a higher probability of beating the sector benchmark despite the fact that only moderate level of accuracy is required to obtain positive potential gains on average. Even though the average excess returns are positive for most of the permutations simulated, they represent results of a significant number of simulations far beyond the number of trials available to any investor. Thus, according to the win/loss ratio, the likelihood of benefiting from sector timing requires a significant forecasting ability. To conclude, potential gains to sector timing in Taiwan are only available to market timers who have significant forecasting ability after transaction costs are taken into consideration. Asset allocation amongst countries has become less effective due to globalization. Studies on the effective sector allocation or sector timing strategies are areas in need of further research.

\section{References}

Barber, B. M., Lee Y., Liu Y. \& Odean, T. (2005). Who loses from trade? Evidence from Taiwan. UC-Davis, Davis, California.

Barboza, D., Lattman, P. \&Rampell, C. (2012). How the U.S. lost out on iPhone work. New York Times, The iEconomy, Part 1: An Empire Built Abroad, January 21.

Bauer, R. J. \& Dahlquist, J. R. (2001). Market timing and roulette wheels. Financial Analysts Journal, 57(1), 28-40.

Chen, S. \& Chen, M. (2011). Does market timing make sense in Taiwan? The $11^{\text {th }}$ International DSI and the $16^{\text {th }}$ APDSI Joint Meeting, July 12-16. Taipei.

Chen, D., Chuang, C., Lin, J. \& Lan, C. (2013). Market timing and stock selection ability of mutual fund managers in Taiwan: applying the traditional and conditional approaches. International Research Journal of Applied Finance, 4(1), 75-98.

Chua, J. H., Woodward, R. S. \& To, E. C. (1987). Potential gains from stock market timing in Canada. Financial Analysts Journal, 43(5), 50-56.

Clarke, R. G., FitzGerald, M. T., Berent, P. \& Statman, M. (1989). Market timing with imperfect information. Financial Analysts Journal, 45(6), 27-36. 
De Bondt, W. F. M. \&Thaler, R. H. (1985). Does the stock market overreact? Journal of Finance, 40(3), 793805.

De Bondt, W. F. M. \& Thaler, R. H. (1987). Further evidence on investor overreaction and stock market seasonality. Journal of Finance, 42(3), 557-581.

De Chassart, M. D. \& Firer, C. (2001), Market timing under different market conditions. Investment Analysts Journal, 54, 19-31.

Droms, W. G. (1989). Market timing as an investment policy. Financial Analysts Journal, 45(1), 73-77.

Fama, E. F. (1970). Efficient capital markets: a review of theory and empirical work. Journal of Finance, 25, 383-417.

Jegadeesh, N. \& Titman, S. (1993). Returns to buying winners and selling losers: implications for stock market efficiency. Journal of Finance, 48(1), 65-91.

Jeong, D. (2012). The IT industry in Northeast Asia: present and future. SERIQ Quarterly, 10-21 January.

Kester, G. W. (1990). Market timing with small versus large-firm stocks: potential gains and required predictive ability. Financial Analysts Journal, 46(5), 63-69.

Sharpe, W. F. (1975). Likely gains from market timing. Financial Analysts Journal, 31(2), 60-69.

Shilling, A. G. (1992). Market timing: better than a buy-and-hold strategy. Financial Analysts Journal, 48(2), 46-50. 